\title{
LA INTERDEPENDENCIA ENTRE EL DERECHO INTERNACIONAL Y EL DERECHO COMUNITARIO EUROPEO
}

\author{
José B. Acosta EstéveZ*
}

RESUMEN: El derecho comunitario europeo es un particularismo jurídico que coexiste con el derecho internacional general, y cuyo resultado es la existencia de la Comunidad Europea como organización internacional de integración. La coexistencia del derecho comunitario europeo y del derecho internacional conlleva la existencia de una interrelación entre ambos ordenamientos jurídicos, incidiendo este último sobre aquél y aportando el primero numerosas innovaciones sobre las tradicionales instituciones iusinternacionalistas. Por consiguiente, el derecho comunitario europeo se configura como un subordenamiento jurídico del derecho internacional, si bien autónomo y propio de la Unión Europea.

ABSTRACT: European community law is a specific legal system that coexists with general international law, the result of which is the existence of the European Community as an international organisation of integration. The coexistence of European community law and international law entails the existence of an interrelationship between both legal codes, with the latter influencing it and the former contributing numerous innovations in the traditional institutions of international law. Consequently, European community law is shaped as a legal sub-code of international law, albeit autonomous and belonging to the European Union.

RÉSUMÉ: Le droit communautaire européen est un particularisme juridique, qui coexiste avec le droit international général, et dont le résultat est l'existence de la Communauté Européenne en tant qu'organisation internationale d'intégration. La coexistence du droit communautaire européen et du droit international implique l'existence d'une interrelation entre les deux législations, ce dernier influençant le premier et le premier apportant au dernier de nombreuses innovations par rapport aux institutions du droit international traditionnelles. Par conséquent, le droit communautaire européen se présente comme une sous-législation du droit international bien qu'étant autonome et propre à l'Union Européenne.

* Profesor titular de derecho internacional público y relaciones internacionales. 
SUMARIO: I. Introducción. II. El derecho comunitario europeo como subordenamiento jurídico del derecho internacional. III. La incidencia del derecho comunitario europeo en el derecho internacional. IV. Consideraciones finales.

\section{INTRODUCCIÓN}

Como señalara en su día Iglesias Buhiges, ${ }^{1}$ no puede ignorarse que el contenido particular de los tratados constitutivos de las comunidades europeas los diferenciaba claramente de los tratados internacionales tradicionales. Además, en tanto que organización internacional, las referidas comunidades muestran rasgos específicos que las alejan de las organizaciones internacionales tradicionales. A partir de esta circunstancia se plantea la interrelación existente entre el derecho internacional privado (DIP) y el derecho comunitario europeo (DCE), esto es, el ordenamiento jurídico europeo es un ordenamiento jurídico autónomo y ajeno al DIP o, por el contrario, se trata de un subordenamiento jurídico de éste. Al respecto, debe recordarse que los tratados constitutivos de la CECA, CEE y CEEA creaban dichas organizaciones internacionales y las dotaban de personalidad jurídica internacional. Posteriormente, en virtud del Tratado de la Unión Europea, de 9 de febrero de 1992, la Comunidad Europea del Carbón y del Acero, la Comunidad Económica Europea y la Comunidad Europea de la Energía Atómica pasaron a integrar la Unión Europea (UE). En consecuencia, el punto de partida de la Comunidad Europea $-\mathrm{y}$ UE - y del ordenamiento jurídico comunitario se encuentra en el DIP. Empero, a pesar de ser evidente tal circunstancia, ¿cabe sostener la independencia del DCE frente al DIP?

La respuesta a la cuestión planteada, tal como se desprende del título de la primera parte del presente trabajo, es negativa: el ordenamiento jurídico comunitario, si bien es autónomo, no es independiente del DIP, sino que se configura como un subordenamiento jurídico de éste. Esta postura tiene su razón de ser en la circunstancia de que el DCE es el resultado de un particularismo jurídico que coexiste con el denominado DIP general. Esta coexistencia queda plasmada, por una parte, en la primacía del DIP frente al DCE y en las particularidades que este último

1 Iglesias Buhigues, J., "La nature juridique du droit communautaire", Cahiers de Droit Européen, 1968, p. 507. 
presenta en relación con el DIP. Por otra, la interrelación o influencia recíproca entre el DIP y el ordenamiento jurídico comunitario conlleva que éste tenga una incidencia sobre aquél. Incidencia que se manifiesta en diferentes ámbitos tradicionales del DIP, tales como en los mecanismos de cooperación y las competencias de las organizaciones internacionales, el derecho de los tratados, el derecho de legación y la protección diplomática.

\section{EL DERECHO COMUNITARIO EUROPEO COMO SUBORDENAMIENTO JURÍDICO DEL DERECHO INTERNACIONAL}

En esta primera parte se tratan las cuestiones relativas a la relación existente entre el ordenamiento jurídico comunitario y el ordenamiento jurídico internacional. A partir de este planteamiento se analizan las cuestiones relativas a la consideración del DCE como particularismo jurídico; el DCE como ordenamiento jurídico y como ordenamiento jurídico de la UE; la primacía del DIP frente al DCE y, por último, las particularidades del DCE en relación con el DIP público. Las cuestiones enunciadas permitirán establecer si el DCE es un ordenamiento jurídico $\mathrm{y}$, en su caso, si se trata de un ordenamiento jurídico independiente del DIP o, por el contrario, se está en presencia de un subordenamiento jurídico del DIP. Por otra parte, a pesar de que el DCE nació en el seno del DIP, huelga decir que la relación existente entre ambos no está exenta de complicaciones motivadas en gran medida por la compleja estructura institucional de la UE, de una parte, y por tener el DCE rasgos característicos resultantes de su estrecha relación con los ordenamientos jurídicos de los Estados miembros, de otra.

\section{El derecho comunitario europeo como particularismo jurídico}

Los Estados aceptan que sus relaciones mutuas sean reguladas por unas reglas universales (sociedad internacional) y otras reglas particulares propias a sociedades más restringidas (sociedades particulares, regionales). En atención a esta distinción cabe hablar de un derecho internacional general, encargado de regular las relaciones de la sociedad internacional, y unos derechos internacionales particulares, resultantes de la formación de ciertas afinidades entre Estados. Desde el punto de vista de la norma, atendiendo al universalismo y al particularismo, puede esta- 
blecerse la distinción entre normas universales o generales y normas particulares. Así pues, desde la perspectiva del contenido del DIP, junto al ordenamiento jurídico internacional común o general coexisten diferentes subordenamientos jurídicos particulares.

Atendiendo al ámbito de aplicación de las normas internacionales cabe distinguir entre normas universales o generales y normas particulares, reflejando estas últimas las realidades sociales y normativas existentes en la sociedad internacional contemporánea. Este particularismo jurídico, como señala Díez de Velasco, ${ }^{2}$ se caracteriza por los siguientes rasgos: 1) La restricción del ámbito de validez y número de sujeto entre los que son válidas las normas particulares; 2) El uso del tratado como instrumento básico y primordial de creación y formación de normas particulares, aunque no sea su única fuente; y 3) El objeto heterogéneo de las normas particulares, ya que son estas normas las que mejor reflejan la expansión y diversificación ratione personae et materiae del DIP. Por consiguiente, el DCE es susceptible de ser considerado como un particularismo jurídico en contraposición con el universalismo, pues el DCE se caracteriza por los siguientes rasgos: 1) Atendiendo al ámbito geográfico, el DCE es un derecho internacional regional o particular propio de una parte del continente europeo; 2) Sobre la base de la producción normativa, el DCE es un derecho elaborado en el seno de una organización internacional; 3) La creación de las normas particulares del DCE tienen su razón de ser en los tratados constitutivos de las comunidades europeas $\mathrm{y}$ en los procedimientos de elaboración normativa previstos en los mismos; y 4) Las normas particulares del DCE reflejan la expansión y diversificación ratione personae et materiae del DIP, pues desde el plano de la sectorialización operada en este último, el DCE es una rama específica del DIP.

Una vez admitido que en el ordenamiento jurídico internacional coexiste lo jurídico general y lo jurídico regional o particular; debe afirmarse seguidamente que ello no supone la existencia de dos tipos de DIP, sino la presencia de dos clases de reglas. Atendiendo al número de destinatarios de las normas, éstas pueden ser generales o particulares. Las primeras son predicables de todos los Estados por haberse formado gracias al consensus de éstos. Las segundas, por el contrario, tienen un destinata-

2 Díez de Velasco, M., Instituciones de derecho internacional público, Madrid, Tecnos, 2003, p. 81 . 
rio particular, pues son aplicables a un grupo perfectamente determinado e individualizado. Así, la heterogeneidad da lugar a los particularismos que, desde el punto de vista jurídico, provocan la aparición de ordenamientos jurídicos particulares de DIP (como el ordenamiento jurídico comunitario) que coexisten junto al DIP general. De tal manera que, dentro del mismo ordenamiento jurídico, por el ámbito de validez personal podrían distinguirse dos clases de reglas: la general y la particular.

\section{El derecho comunitario europeo como ordenamiento jurídico de la Unión Europea}

En este apartado se contemplan tres circunstancias diferentes pero estrechamente vinculadas: en primer lugar, la consideración del DCE como un ordenamiento jurídico, esto es, el DCE no es un conglomerado de normas internacionales particulares, sino que las mismas conforman un ordenamiento jurídico con los rasgos comunes inherentes en los ordenamientos jurídicos estatales e internacionales. En segundo lugar, la consideración del DCE como el ordenamiento jurídico de la UE, circunstancia que implica la existencia de características propias del ordenamiento jurídico comunitario. En tercer lugar, la consideración del ordenamiento jurídico comunitario como un subordenamiento jurídico del ordenamiento jurídico internacional.

\section{A. El derecho comunitario como ordenamiento jurídico}

En 1917, Romano plasmó el término “ordenamiento jurídico" y la idea que encierra el mismo:

Cuando se habla del derecho italiano o del derecho francés, no es verdad que se piense sólo en una serie de reglas, ni que nos representemos únicamente los volúmenes que forman las colecciones oficiales de leyes y decretos. En lo que se piensa por los juristas, y más aún por los profanos ajenos a las definiciones de que hablamos, es en algo más dinámico y vital: es, en primer lugar, en la compleja y variada organización del Estado italiano o francés; en los numerosos mecanismos o engranajes, en las relaciones de autoridad y de fuerza que producen, modifican, aplican y garantizan las normas jurídicas, pero que no se identifican con ellas. En otros términos, el ordenamiento jurídico así entendido en su conjunto, es una entidad que se mueve en parte según las normas como si fueran las piezas de un tablero de ajedrez, normas que de este modo resultan más bien el 
objeto, e incluso el medio de su actividad, que no un elemento de su estructura. ${ }^{3}$

Así, el derecho antes que ser norma y que implicar una o varias relaciones sociales, es sobre todo organización, estructura, posición de la sociedad misma en que se desarrolla, y que precisamente el derecho constituye como unidad, como ente con sustantividad propia.

Ahora bien, cabe advertir que el conjunto de normas es insuficiente, siendo necesario complementarlo con otros elementos. Así, el ordenamiento jurídico comunitario no es un mero agregado de normas, sino que éstas lo son porque se encuentran insertas en un ordenamiento jurídico concreto, es decir, "cada norma o grupo de normas adquiere sentido dentro del conjunto total de normas de la organización... La visión de conjunto de las reglas jurídicas la ofrece el ordenamiento jurídico", 4 que como tal precede a la norma y ha tenido que definirla previamente mediante los mecanismos de producción normativa y en cuyo ámbito únicamente cobra todo su sentido. Desde esta óptica, el ordenamiento jurídico es sustancialmente organización de un ente social como tal ente y entre sus miembros. El ordenamiento jurídico comunitario sería la expresión jurídica de la UE.

El derecho es un conjunto normativo (las normas son el elemento principal), pero no cabe reducirlo o limitarlo únicamente a normas. Las normas son una parte del ordenamiento jurídico, pero no agotan, en su totalidad, la integridad del mismo. El ordenamiento jurídico es algo distinto de las normas que lo integran: el ordenamiento se sirve de ellas y las abarca, pero al mismo tiempo, las rebasa y supera. ${ }^{5} \mathrm{Al}$ tenor de este planteamiento, la doctrina ha elaborado diferentes tesis ${ }^{6}$ en orden a ofrecer un concepto de ordenamiento jurídico que no suponga un mero conjunto normativo, pues al designarse bajo esta denominación al conjunto de normas que en un determinado momento histórico rigen en una socie-

3 Romano, S., El ordenamiento jurídico, Madrid, Instituto de Estudios Políticos, 1963, pp. 88 y 113 .

4 Castro y Bravo, F. de, Derecho civil de España, Madrid, Civitas, 1984, p. 57.

5 Biscaretti Di Ruffia, P., Derecho constitucional, Madrid, Tecnos, 1987, p. 30.

6 Al respecto, Bobbio, N., Contribución a la teoría del derecho, Valencia, Fernando Torres, 1980; Dworkin, R., Los derechos en serio, Barcelona, Ariel, 1984; Hart, H., El concepto de derecho, Buenos Aires, Abeledo Perrot, 1977; Kelsen, H., Teoria pura del derecho, México, UNAM, 1982; Kelsen, H., Teoría general del derecho y del Estado, México, UNAM, 1983; Nino, C., Introducción al análisis del derecho, Barcelona, Ariel, 1983. 
dad (por ejemplo, el ordenamiento jurídico español) se está incurriendo en una simplificación. El ordenamiento jurídico es algo más que un conjunto normativo. Esto significa que el ordenamiento jurídico internacional no puede ser entendido tan sólo como un conjunto normativo pues, como advierte Bobbio, ${ }^{7}$ tal conjunto se ha de estudiar pero si se tiene en cuenta un "todo" más vasto que lo comprende; por "todo" se entiende el ordenamiento jurídico. En consonancia con lo indicado, puede decirse con Sánchez Rodríguez que "el concepto de ordenamiento jurídico presenta una conexión íntima con la idea de sistema organizado" y, por esto, "tal concepto hace referencia al conjunto del bloque normativo considerado como un todo, en el que sus distintas partes deben encontrarse en armónica coherencia entre sí". ${ }^{8}$ En tanto que ordenamiento jurídico, el DCE es algo más que una suma de normas.

Con carácter general, puede decirse que el derecho es un orden de la convivencia social inspirado en unos criterios o principios. Este orden presupone la solución de los conflictos de intereses que dicha convivencia determina y la organización estable de unos mecanismos para llegar a tales soluciones, se encuentra formado por un sistema de principios y de normas a los cuales la convivencia se ha de atener y conforme a las cuales se han de solucionar los conflictos que pueda suscitar - en este contexto tiene cabida el DCE- A partir de esta afirmación, el ordenamiento jurídico está formado por principios y normas encaminadas a la ordenación de la convivencia, solución de conflictos y consecución de intereses, pero además de este conjunto normativo cabe incluir los valores fundamentales y convicciones imperantes dentro de una sociedad, que son los que dan sentido al conjunto normativo.

El ordenamiento jurídico constituye una realidad orgánica en tanto que al conjunto normativo se añade la manera como las normas se crean (procedimientos de producción) y aplican (mecanismos de aplicación) en la realidad social. En este contexto, el ordenamiento jurídico implica una serie de interrelaciones, que lo convierten en un todo unitario y coherente, y desde el cual se puede dar respuesta a los principales problemas que

7 Bobbio, N., Teoría general del derecho, Madrid, Debate, 1991, p. 154.

8 Sánchez Rodríguez, L., "Los tratados internacionales como fuente del ordenamiento jurídico español", Cursos de derecho internacional de Vitoria Gasteiz, Bilbao, Universidad del País Vasco, 1994, p. 143. 
el derecho plantea. ${ }^{9}$ Por tanto, junto al conjunto normativo, cabe sostener la existencia de una organización que lo crea y hace valer; esto es, el DCE no puede ser sólo los Tratados Constitutivos o los reglamentos adoptados, desprendido de sus mecanismos de creación o de aplicación: el DCE se construye en torno a la idea de la UE (ubi ius ibi societas y ubi societas ibi ius).

La conjunción o interrelación de todos los elementos indicados lleva a la doctrina a formular una concepción sistemática del ordenamiento jurídico, que permita entender el mismo como algo perfecto, como un todo unitario y sistemático, esto es, la doctrina procede a intentar determinar la estructura del ordenamiento jurídico. En todo caso, si se tiene presente la teoría general del derecho, cabe sostener que el ordenamiento jurídico comunitario se estructura en normas que proclaman derechos e imponen obligaciones (conjunto normativo); procedimientos de creación de normas; mecanismos de aplicación de las normas y principios inspiradores del ordenamiento comunitario en tanto que estándares o reglas indispensables que expresan su estructura. Los elementos indicados no constituyen una mera yuxtaposición desordenada y arbitraria, sino que conforman un todo unitario y sistemático: ${ }^{10}$ el ordenamiento jurídico comunitario. Esta afirmación permite comprender la dinámica normativa del DCE: las normas cambian, pero el ordenamiento jurídico permanece.

Desde la perspectiva de la noción de ordenamiento jurídico, el DCE no es diferente de los derechos internos, pues posee los caracteres fundamentales del derecho. El ordenamiento jurídico comunitario es unitario, coherente y pleno. En este sentido, como señala Campins Eritja, ${ }^{11}$ las características expresadas tienen su reflejo en las siguientes características: 1) La existencia de un sistema de atribución de competencias a las instituciones comunitarias y la consiguiente limitación en el pleno ejercicio de la soberanía de los Estados miembros; 2) La existencia de un sistema institucional para la creación de normas jurídicas comunitarias; 3) La existencia de un mecanismo de control institucional de la aplicación e interpretación del DCE; y 4) La existencia de un procedimiento de revisión

9 Por ejemplo, el poder identificar una norma de ese sistema, individualizar y establecer sus límites frente a otros sistemas no jurídicos - la moral-, establecer una jerarquía de las normas dentro del sistema, etcétera.

10 Reuter, P., Derecho internacional público, Barcelona, Bosch, 1978, p. 38.

11 Campins Eritja, M., "Ordenamiento jurídico comunitario: fuentes", Lecciones de derecho comunitario europeo, Barcelona, Ariel, 1995, pp. 85 y 86. 
de los tratados constitutivos, en el que participan las instituciones comunitarias y los Estados miembros. En fin, el DCE posee las cualidades de un ordenamiento jurídico, es decir, en palabras de Isaac, se trata de "un conjunto organizado y estructurado de normas jurídicas que posee sus propias fuentes, dotado de órganos y procedimientos aptos para emitirlas e interpretarlas, así como hacer constatar y sancionar, llegado el caso, las violaciones". ${ }^{12}$

\section{B. El derecho comunitario como ordenamiento jurídico de la Unión Europea}

Como afirma el adagio latino: ubi societas ibi ius (donde hay sociedad hay derecho). Un análisis realista del fenómeno jurídico - internacional y comunitario - se encuentra íntimamente vinculado a la base social respecto a la que éste opera, ya que los ordenamientos jurídicos se encuentran condicionados por los particulares rasgos característicos del grupo social del que emanan y, como las sociedades evolucionan, su ordenamiento jurídico está en función de la dinámica de aquéllas: según sea la sociedad, así será el derecho. De este modo:

Dentro de la amplia libertad de disposición que el DI universal y general deja a sus sujetos, éstos pueden constituir dentro de sociedades regionales regímenes jurídicos del mismo carácter, regional. Con ello, sea por confluir un espacio geopolítico continuo con problemas propios, sea por su homogeneidad política, económica, social o cultural, estos sujetos, o bien adaptan las normas generales a su especificidad, o bien van más allá de esas normas, estrechando su cooperación o anticipando soluciones que, luego, pueden convertirse en universales. ${ }^{13}$

Así, el DCE es un exponente del denominado derecho internacional regional, pues él mismo es resultado de un proceso evolutivo de integración económica y política en un grupo de Estados europeos - integrantes de la UE-.

El Tribunal de Justicia de la Comunidad Europea (TJCE) declaró que el DCE no sólo trata de "un nuevo ordenamiento jurídico de derecho internacional" - Sentencia Van Gend el Loos, de 5 de febrero de 1963

12 Isaac, G., Manual de derecho comunitario general, Barcelona, Ariel, 1997, p. 139.

13 Remiro Brotons, A. et al., Derecho internacional, Madrid, McGraw-Hill, 1997, p. 18. 
(As. 26/62) - Posteriormente, en la Sentencia Costa v. ENEL, de 15 de julio de 1964 (As. 6/64), el citado órgano jurisdiccional afirmó que el DCE es "un ordenamiento jurídico propio, integrado en el sistema jurídico de los Estados miembros". En el contexto descrito y en sentido amplio, el DCE se presenta como el ordenamiento jurídico propio de la UE. En consecuencia, el DCE se configura como el "conjunto de normas jurídicas destinadas a la creación y funcionamiento de las comunidades europeas y a la realización progresiva del objetivo comunitario básico de integración económico-social entre los Estados miembros". ${ }^{14} \mathrm{Y}$, en tanto que ordenamiento jurídico, al igual que el DIP y los derechos internos, el DCE se estructura en torno a los sujetos destinatarios de las normas, los procedimientos de producción normativa y los mecanismos de aplicación de las normas. Por consiguiente, la estructura de la sociedad es determinante a la hora de conformar el DIP y, en su caso, el DCE en tanto que éstos están condicionados por las características propias del grupo social del que provienen y a los que se aplican.

El DCE no es un conglomerado de normas, sino un ordenamiento jurídico, en tanto que en el mismo concurren las siguientes características: unidad, coherencia y plenitud. Pero, además de estas características comunes a todos los ordenamientos jurídicos (internos e internacionales), el ordenamiento jurídico comunitario reviste características particulares, ${ }^{15}$ que responden a las características propias de la UE, pero que lo diferencian de los derechos estatales y del DIP. ${ }^{16}$ Así, estas características particulares, el efecto directo de sus normas y su primacía sobre los ordenamientos jurídicos de los Estados miembros, son, en palabras de Louis, ${ }^{17}$ los pilares del ordenamiento jurídico comunitario que sostienen el conjunto del edificio de la UE.

El DCE es "un ordenamiento autónomo, pero llamado a incidir en los ordenamientos de los Estados miembros. Este cuerpo jurídico común,

14 Plender, R., Introducción al derecho comunitario europeo, Madrid, Civitas, 1985, p. 32.

15 Un sector doctrinal niega todo rasgo particular del ordenamiento jurídico comunitario. A título de ejemplo, Balladore Pallieri, G., "Le Comunità Europee e gli ordinamenti interni degli Stati membri”, Diritto Internazionale, 1961, núm. 15, pp. 3 y ss.

16 Así, por ejemplo, el Tribunal Superior Administrativo de la antigua República Federal de Alemania ha declarado que el derecho comunitario europeo constituye "un ordenamiento jurídico distinto, cuyas disposiciones no pertenecen ni al derecho internacional ni al derecho interno de los Estados miembros", Common Market Law Review, 1967, p. 483.

17 Louis, J., El ordenamiento jurídico comunitario, Bruselas, Comisión de las Comunidades Europeas, 1987, p. 8. 
paradoja de autonomía e integración, tiende a excluir la regulación nacional de los ámbitos por él abarcados" 18 o, como afirma Plender, ${ }^{19}$ a la luz de la evolución histórica operada en el seno de la Comunidad Europea, el DCE supone la plasmación jurídica de una aspiración de integración política a través de la tarea de integración económico-social de los Estados miembros. Y, atendiendo a la circunstancia de que el DCE es un ordenamiento jurídico y la Comunidad Europea es una organización internacional de integración, algunos autores, como Monaco, ${ }^{20}$ han sostenido que el ordenamiento jurídico comunitario es un ordenamiento jurídico de integración, ya que es el instrumento mediante el cual se trata de conseguir una integración jurídica entre ordenamientos jurídicos distintos. Este carácter integrador del ordenamiento jurídico comunitario queda de manifiesto en su inmediatez, es decir, en su aplicación directa sin necesidad de intervención del Estado. ${ }^{21}$

\section{El ordenamiento jurídico comunitario como subordenamiento jurídico del ordenamiento jurídico internacional}

En 1994, Capottorti ${ }^{22}$ se preguntaba ¿concierne la integración europea al DIP? Y, si bien algún autor, como Constatinesco, ${ }^{23}$ sostiene que ya no pertenece a la esfera del DIP, la respuesta a esta cuestión debe ser afirmativa, porque el DIP es el germen que en un primer momento posibilitó la Comunidad Europea y posibilita la UE. La UE se desenvuelve en el seno de la sociedad internacional contemporánea, por un lado, y la interrelación entre ordenamiento jurídico comunitario y el ordenamiento jurídico internacional es una realidad, por otro.

El DCE es el motor de la integración europea, pero esto no es óbice para negar que se trate de un subordenamiento jurídico del ordenamiento jurídico internacional, esto es, una subespecie internacional sui generis "cuya esencia jurídica emerge de su profunda y compleja interrelación

18 Alonso García, R., Derecho comunitario, derechos nacionales y derecho común europeo, Madrid, Civitas, 1989, p. 33.

19 Plender, R., Introducción al derecho comunitario europeo, Madrid, Civitas, 1985, p. 32.

20 Monaco, R., Diritto delle Comunità Europee e diritto interno, Milán, Giuffrè, 1967.

21 Visscher, C. de, Teorías y realidades en derecho internacional público, Barcelona, Bosch, 1962 , pp. 250 y 251.

22 Capottorti, F., "Cours général de droit international public", RCADI, 1994, t. IV, p. 322.

23 Constatinesco, L., "La spécificité du droit communautaire", Revue Trimistrielle de Droit Européen, 1964, p. 9. 
con los ordenamientos jurídicos internos". ${ }^{24}$ Empero, no debe olvidarse que las comunidades europeas son fruto de los actos constitutivos denominados tratados internacionales, cuyas revisiones dependen de los Estados miembros, y que las competencias de estas comunidades, sobre las que se elabora toda la ingeniería comunitaria, dependen de la voluntad de los Estados miembros (competencias de atribución). Así las cosas, los Estados miembros son los "señores de los tratados" 25 constitutivos y, por ende, la UE y su ordenamiento jurídico se encuentran ubicadas en sede iusinternacionalista. En otras palabras, la Comunidad Europea es una organización internacional — distinta de las tradicionales - ya que no ha trascendido de tal categoría y, por consiguiente, el DIP constituye su fundamento.

Que el DCE es un ordenamiento jurídico nuevo y propio de la UE está fuera de toda duda pero, en todo caso, es un ordenamiento autónomo del DIP, ya que el mismo no es autosuficiente:

No posee los rasgos propios de un sistema cerrado sino, a lo sumo, semi-cerrado. En otras palabras, incluso en el ámbito del pilar comunitario queda un cierto espacio para el juego de normas de derecho internacional general... El carácter semi-cerrado del DCE se aprecia... incluso al estudiar a fondo los mecanismos que ofrece el DCE en materia de arreglo de controversias y de responsabilidad de los Estados miembros por infracción de sus obligaciones (sector que, a primera vista, se presenta particularmente autosuficiente). Es verdad que, como se ha dicho, en caso de infracción del DCE por un Estado miembro, los demás Estados miembros no pueden acudir a otros mecanismos que los previstos en los artículos 169 y 170 del TCE (o, eventualmente, someter la controversia al TJCE mediante compromiso, de conformidad con el artículo 182), quedando además excluido el recurso a las contramedidas. Es también cierto que, como hemos tenido ocasión de recordar, en caso de violación del DCE por un Estado miembro se abre en favor de los particulares la posibilidad de una reparación de los daños causados por los cauces procesales del derecho interno. Pero ¿no es igualmente cierto que en tales supuestos el DCE no está cerrado a la posible exigencia por un Estado miembro de una reparación de los daños que para él se derivan de la infracción del otro? Permítanme que recuerde una

24 Mangas Martin, A. y Liñan Nogueras, D., Instituciones y derecho de la Unión Europea, Madrid, McGraw-Hill, 1999, p. 168.

25 Expresión utilizada por el Tribunal Constitucional Federal Alemán en su sentencia de 12 de octubre de 1993. Revista de Instituciones Europeas, núm. 3, 1993, pp. 975 y ss. 
vez más los ataques sufridos por transportistas españoles en territorio francés. ${ }^{26}$

Los intentos de desvincular el DCE del DIP son resultado de la consideración del DCE como un ordenamiento jurídico nuevo y propio, características que propician su especificidad y autonomía frente al DIP y a los derechos internos. En concreto, la relación DIP/DCE presenta numerosas dificultades como resultado de la compleja estructura institucional de la UE, es decir, estamos en presencia de una estructura que se elaboró sobre la base de normas jurídico internacionales, pero cuyo desarrollo se lleva a término a través de una especial relación con los derechos internos de los Estados miembros. ${ }^{27}$ Empero, como escribe Louis:

El carácter específico del ordenamiento jurídico comunitario se debe, en especial, a que el derecho internacional no está destinado a desempeñar un gran papel en las relaciones entre las instituciones y los Estados miembros, por una parte, ni en el campo de aplicación de los Tratados entre Estados miembros, por otra. Debido a la naturaleza de las competencias comunitarias, los contactos con el derecho interno son mucho más fructíferos. No obstante, el desarrollo de la acción de las instituciones en los campos antiguamente reservados a los Estados y la puesta en práctica de la personalidad jurídica internacional de la comunidad, hacen que ésta se manifieste cada vez más en la esfera internacional y, por ello, que se rija por las normas que en ella se aplican. ${ }^{28}$

En todo caso, recordar que en el seno del DCE operan categorías e instituciones propias del DIP. En tanto que particularismo jurídico que coexiste con el derecho internacional general, el ordenamiento jurídico comunitario se configura como un subordenamiento jurídico del ordenamiento jurídico internacional, originando normas comunitarias que son normas internacionales particulares, esto es, el DCE, en tanto que derecho internacional particular, crea normas internacionales que se aplican en la UE (instituciones comunitarias y Estados miembros).

26 Díez-Hochleitner, J., "La interdependencia entre el derecho internacional y el derecho de la Unión Europea", Cursos de derecho internacional de Vitoria Gasteiz (1998), Madrid, Tecnos, 1999, p. 68 .

27 Mangas Martin, A y Liñan Nogueras, D., Instituciones y derecho de la Unión Europea, Madrid, McGraw-Hill, 1999, p. 191.

28 Louis, J., El ordenamiento jurídico comunitario, Bruselas, Comisión de las Comunidades Europeas, 1987, p. 81 . 


\section{La primacía del derecho internacional frente al derecho comunitario europeo}

Escribe Díez-Hochleitner que "por mucha autonomía que adquiera el derecho de la UE respecto del derecho internacional, éste no le podrá ser nunca ajeno. La UE precisa de una acción exterior que ha de acomodarse a este ordenamiento. En consecuencia, el derecho de la UE no podría nunca ignorar al derecho internacional y su primacía sobre él". ${ }^{29}$ A partir de esta afirmación puede constatarse:

\section{A. La subordinación del derecho comunitario europeo al derecho internacional general}

El DCE está sujeto al derecho internacional universal o general (aplicable a todos los sujetos internacionales en tanto que su formación responde al acuerdo general de éstos) en la misma medida en que lo están los sujetos internacionales (Estados y organizaciones internacionales), ya que éste se impone a sus destinatarios sin necesidad de una disposición de sumisión expresa al derecho internacional universal. La imposición de dicho derecho viene determinada en el mismo y no por los ordenamientos jurídicos estatales o de organizaciones internacionales. En consecuencia, con independencia de la inexistencia de una disposición de sumisión comunitaria, el DCE está sujeto al derecho internacional universal. A mayor abundamiento, el TJCE "reconoce la subordinación del DCE al DIP que vincula a la Comunidad... Las comunidades están sometidas al derecho internacional general" ${ }^{30} \mathrm{y}$, así por ejemplo, dicho órgano jurisdiccional ${ }^{31}$ admite la aplicación de las normas consuetudinarias internacionales y de los principios generales de DIP a la UE y, asimismo, reconoce que el DIP universal vincula a la UE. En la Sentencia Kramer, ${ }^{32}$ el TJCE señaló que en la medida en que la Comunidad Europea asumía las

29 Díez-Hochleitner, J., "La interdependencia entre el derecho internacional y el derecho de la Unión Europea", Cursos de derecho internacional de Vitoria Gasteiz (1998), Madrid, Tecnos, 1999, p. 68.

30 Rodríguez Iglesias, G., "El derecho comunitario europeo", Las organizaciones internacionales, Madrid, Tecnos, 1977, p. 528.

31 Asuntos conjuntos 21/72 a 24/72, International Fruit Cy, Sentencia GATT, Rep. TJCE 1972, p. 1226.

32 Rep. TJCE 1976, pp. 1279 y ss., y 1311. 
competencias de los Estados miembros, estaba limitada por las mismas disposiciones que se imponían a éstos.

\section{B. El derecho de los tratados y el derecho comunitario europeo}

Un amplio sector doctrinal sostiene que el derecho de los tratados obliga a la $U^{33}$ y, en palabras de Mangas Martin y Liñan Nogueras, el DCE "tanto material como formalmente se trata de normas jurídico-internacionales y, en consecuencia, regidas por las normas de derecho internacional general aplicables a los tratados internacionales". ${ }^{34}$ ¿Qué ocurre si el TJCE anula las decisiones por las que la comisión y el consejo de la Comunidad Europea aprobaron un tratado internacional celebrado por ésta con un tercer Estado? A nivel práctico del foro, en las sentencias de 9 de agosto de 1994 (As. C-327/91) ${ }^{35}$ y 7 de marzo de 1996 (AS. C-360/93), ${ }^{36}$ el TJCE anuló, respectivamente, el acuerdo entre la comisión y Estados Unidos sobre derecho de la competencia y el acuerdo con Estados Unidos sobre contratación pública al comprobar que dichos tratados no habían sido concluidos de conformidad con las disposiciones del DCE, esto es, los tratados no cumplían las condiciones necesarias para ser vinculantes para las instituciones comunitarias y los Estados miembros y, en consecuencia, no concurrían en los mismos los requisitos necesarios, estipulados en los apartados 1 a 6 del artículo 300 del TCE, para su incorporación en el ordenamiento jurídico comunitario (artículo 300.7 TCE). Ahora bien, se habla de tratados no válidamente celebrados desde la perspectiva del DCE y no desde el punto de vista del derecho de los tratados. En otros términos, el TJCE solamente se limitó a comprobar si en la celebración de los indicados tratados se había respetado las disposiciones comunitarias en la materia, llegando a la conclusión de que no eran conformes a DCE y, por tanto, declaró la nulidad de las decisiones de la comisión y del consejo. Pero la declaración de que no eran válidos conforme a DCE no afecta a la esencia de los referidos tratados, es decir, en el ámbito del DIP, dichos tratados siguen teniendo validez.

33 Bernhardt, R., "Las fuentes del derecho comunitario: la 'constitución' de la comunidad", Treinta años de derecho comunitario, Bruselas, Comisión de las Comunidades Europeas, 1981, p. 78.

34 Mangas Martin, A y Liñan Nogueras, D., Instituciones y derecho de la Unión Europea, Madrid, McGraw-Hill, 1999, p. 330.

35 Rep. TJCE, pp. 3641 y ss.

36 Rep. TJCE, pp. 1195 y ss. 
La conclusión que se desprende del planteamiento expresado es que la declaración de nulidad comunitaria no conlleva que el tratado deba dejarse de aplicar a nivel internacional. Desde este punto de vista, las obligaciones contraídas por la UE por un tratado internacional, aunque el TJCE declare que no ha sido válidamente celebrado, tienen que ser cumplidas, pues en caso contrario se producirá un incumplimiento por las instituciones comunitarias que generará una responsabilidad internacional para la UE.

\section{Los límites a la aplicación de las normas comunitarias: las normas de ius cogens y la Carta de las Naciones Unidas}

En tanto que normas particulares, a la hora de su aplicación las normas comunitarias tienen un doble límite: las normas de ius cogens y la Carta de las Naciones Unidas. Los diferentes procedimientos de creación normativa pueden generar normas de ius cogens encaminadas a la consecución de los fines esenciales del DIP; sin embargo, el origen consuetudinario de todas las normas de ius cogens aceptadas en la actualidad como tales es innegable (por ejemplo, los apartados 3 y 4 del artículo 2 de la Carta han recogido unas normas de origen consuetudinario, constitucionalizándolas a posteriori en normas de ius cogens): una norma para ser de ius cogens debe ser universal, ${ }^{37}$ pero no toda norma de derecho internacional general es de ius cogens. Las normas imperativas protegen los intereses esenciales que la sociedad internacional precisa para pervivir, en tanto que son aceptadas y reconocidas por dicha sociedad en su conjunto, derivando de un consenso general de los Estados sobre ciertos valores jurídicos. ${ }^{38}$ Las normas imperativas no admiten acuerdo o pacto en con-

37 El artículo 40 del Proyecto de la CDI, sobre responsabilidad internacional de los Estados, habla expresamente de "obligaciones que emanan de una norma imperativa de derecho internacional general", así pues, cabe preguntarse sobre la posible existencia de normas imperativas que no son de derecho internacional general, esto es, normas de ius cogens regional o particular. A título ejemplificador, en el ámbito de la Comunidad Europea, atendiendo al dictamen 1/91 del TJCE (Recueil 1991, p. I-6084-6113), se ha afirmado la existencia de un ius cogens comunitario o conjunto de valores esenciales para la propia pervivencia de la propia comunidad. En todo caso, el denominado ius cogens regional o particular no sólo carece del rasgo de universalidad propio de las normas imperativas, sino que únicamente puede producir efectos en relación a los Estados que han aceptado su carácter imperativo, pudiendo éstos derogarlo según sus conveniencias y, por ello, este ius cogens regional estará siempre subordinado al ius cogens universal, al que no podrá contradecir.

38 Anuario de la Comisión de Derecho Internacional, vol. I, 1963, pp. 80 y ss. 
trario, ya que protegen los intereses esenciales que la sociedad internacional precisa para su supervivencia y, en consecuencia, imposibilitan a los sujetos el sustraerse de las mismas. Dicho de otro modo, las normas imperativas o de ius cogens están por encima de las diferentes voluntades estatales, en tanto que no pueden ser derogadas - carácter inderogable — ${ }^{39}$ mediante los acuerdos de voluntades ${ }^{40}$ entre los Estados, ${ }^{41}$ pues vienen referidas a una serie de valores fundamentales para la sociedad internacional: "ante todo... las normas de ius cogens, al igual que en los ordenamientos internos, suponen un límite a la autonomía de la voluntad; como se ha señalado, constituyen, sin duda alguna, el más fuerte límite que el medio colectivo en que los Estados viven y desenvuelven su actividad impone al relativismo del DIP, al voluntarismo y subjetivismo de los Estados soberanos". ${ }^{42}$ Así pues, el ius cogens se caracteriza precisamente por el hecho de que prohíbe dicha derogación en las relaciones mutuas entre dos Estados. Esto significa que un Estado no puede liberarse de las obligaciones que le impone una norma de ius cogens con respecto a otro Estado ni siquiera mediante un tratado, es decir con el consentimiento de ese otro Estado: éste último no puede renunciar por sí mismo a sus derechos. Por tanto, el DIP no se reduce solamente a ser un producto resultante de la voluntad de los Estados, sobre la base del principio de la soberanía estatal, sino que la existencia del ius cogens conlleva una limitación a la autonomía de la voluntad de los Estados y, desde este aspecto, el ius cogens podría ser considerado un perjuicio a la soberanía de los Estados.

El segundo límite a la aplicación del DCE es la Carta de las Naciones Unidas. Atendiendo a su naturaleza jurídica, la carta es un tratado in-

39 Dominice, C., "The international responsibility of States for breach of multilateral obligations", EJIL, núm. 2, 1999, pp. 358 y 359.

40 CPJI, "Asunto Oscar Chinn", Serie A/B, núm. 63, pp. 149 y 150; CIJ, "Asunto sobre las reservas a la Convención para la Prevención y Represión del Crimen de Genocidio", Recueil, 1951, p. 23; CIJ, "Asunto del derecho de paso por territorio de la India", Recueil, 1960, pp. 34; CIJ, "Asunto del sudoeste africano segunda fase", Recueil, 1966, pp. 258 y ss.; e ICJ, "Asuntos relativos a la plataforma continental del Mar del Norte", Reports, 1969, pp. 24-46.

41 Asimismo, según el artículo 26 del Proyecto de Artículos sobre Responsabilidad del Estado por Hechos Internacionalmente Ilícitos, las circunstancias que excluyen la ilicitud contempladas en dicho proyecto (arts. 20,21, 22, 23, 24 y 25) no excluirán la ilicitud de cualquier hecho de un Estado que no esté en conformidad con una obligación que emana de una norma imperativa de derecho internacional general.

42 Casado Raigón, R., Notas sobre el ius cogens internacional, Córdoba, Universidad de Córdoba, 1991, p. 11. 
ternacional con algunas particularidades especiales ${ }^{43}$ propias de las Constituciones (en el mismo sentido de las Constituciones internas de los Estados) y, por esto, no se ha dudado en decir que es un tratado con alma de Constitución o, en palabras de Pastor Ridruejo, se trata de "un tratado con rango constitucional". ${ }^{44}$ Esta circunstancia plantea el problema de la incompatibilidad de las obligaciones derivadas de la carta y los acuerdos celebrados por los Estados miembros. La solución aparece proclamada en el artículo 103 de la carta: "en caso de conflicto entre las obligaciones contraídas por los miembros de las Naciones Unidas en virtud de la presente carta y sus obligaciones contraídas en virtud de cualquier otro convenio internacional, prevalecerán las obligaciones impuestas por la presente carta". Por tanto, las obligaciones dimanantes de la carta deben ser consideradas como superiores a las resultantes de otros tratados internacionales $^{45} \mathrm{y}$, en consecuencia, prevalecerán en contra de las mismas. Al tenor de lo expresado, los Estados miembros de la UE, que son también Estados miembros de la ONU, deben hacer prevalecer las obligaciones de la carta y evitar cualquier antinomia al concluir tratados posteriores. $\mathrm{Y}$, en caso contrario, la obligación general de hacer prevalecer la carta es superior a las obligaciones derivadas del DCE, que tienen un carácter especial. En fin, las obligaciones derivadas de la carta son superiores a toda otra obligación contraria a las mismas generada en virtud de cualquier instrumento internacional, incluidos los propios del DCE.

\section{Las particularidades del derecho comunitario europeo en relación con el derecho internacional}

En tanto que ordenamiento jurídico aplicable en el grupo social internacional en un momento histórico determinado, ${ }^{46}$ el DIP se encuentra íntimamente vinculado con su propia base social y con las mutaciones que se operan en su seno; es decir, dicho derecho deberá responder a la

43 Al respecto, artículos 2.6, 103, 108 y 109.

44 Pastor Ridruejo, J., Curso de derecho internacional público y organizaciones internacionales, Madrid, Tecnos, 2003, p. 681.

45 En este sentido, se ha pronunciado el TIJ en la sentencia de 26 de noviembre de 1984, relativa a CIJ, "Asunto de las actividades militares y paramilitares en Nicaragua y contra ella", Recueil, 1984, pp. 192 y ss.; y ordenanzas de 14 de abril de 1992 en el CIJ, "Asunto sobre cuestiones de interpretación y aplicación de la Convención de Montreal de 1971 resultantes del incidente aéreo de Lockerbie", Recueil, 1992.

46 González Campos, J., Curso de derecho internacional público, Oviedo, Universidad de Oviedo, 1975, vol. I, p. 36. 
concreta realidad social internacional. ${ }^{47}$ Así pues, el DIP será el derecho aplicable a la sociedad internacional. En atención a este planteamiento, a partir de su consideración como ordenamiento jurídico, las características propias del DIP vendrán determinadas por las de la sociedad internacional ya que "si la experiencia histórica demuestra que la vida social se somete a normas jurídicas, también desvela que las características del fenómeno jurídico son determinadas por las de la sociedad cuyas relaciones pretenden regir en un momento dado... El derecho de la sociedad internacional posee unas señas de identidad que lo distinguen de los derechos de las sociedades estatales". ${ }^{48}$ La sociedad internacional existente hasta la Gran Guerra, caracterizada por el reducido grupo de miembros y por su homogeneidad, difiere de la contemporánea que es universal, heterogénea, predominantemente interestatal y escasamente organizada. En atención a estas características de su base social, además de las notas comunes a todo ordenamiento jurídico (unidad, coherencia y plenitud), el DIP reviste unas particularidades, derivadas de la influencia determinante de la soberanía de los Estados en la estructura del DIP, que lo diferencian de los ordenamientos jurídicos internos, es decir, se trata de un ordenamiento presidido por el relativismo, la descentralización y la universalidad.

El relativismo del ordenamiento jurídico internacional es resultado de la soberanía, que se configura como la idea-fuerza en el DIP, ${ }^{49}$ y de la distribución individualista del poder político en la sociedad internacional. Así, de esta manera, el relativismo se perfila como uno de los caracteres básicos de este ordenamiento: "el relativismo del DIP significa que, en principio, para que una obligación se vincule a un Estado o una situación produzca efectos jurídicos respecto de él, es preciso que dicho Estado haya participado en su creación o las haya reconocido"..$^{50}$ Por esto, la consecuencia jurídica más importante resultante del relativismo estriba en poner de manifiesto el valor esencial del acuerdo en DIP.

\footnotetext{
47 Chaumont, CH., "Cours général de droit international public", $R C A D I$, t. 129, 1970, pp. 344 y ss.

48 Remiro Brotons, A., Derecho internacional público. Principios fundamentales, Madrid, Tecnos, 1982, pp. 24 y 25.

49 Chaumont, CH., op. cit., nota 47, pp. 363 y 364.

50 Carrillo Salcedo, J., Soberanía del Estado y derecho internacional, Madrid, Tecnos, 1976, p. 107.
} 
La sociedad internacional se configura como un grupo social en el que el poder político está descentralizado, pues los Estados coexisten en una serie de relaciones de carácter horizontal: la estructura de yuxtaposición implica que éstos no estén unidos entre sí, ni estén sometidos a un poder superior con potestad para crear el derecho. A diferencia de los ordenamientos jurídicos internos, la creación y modificación de las normas jurídicas no podrá ser confiada a un órgano centralizado que actúe en nombre de la sociedad internacional, sino que esta función se plasmará a través de diferentes procedimientos en los que se manifestará el consentimiento estatal, en tanto que las normas de derecho internacional general son creadas y modificadas por el consenso general de los Estados. El carácter descentralizado tiene como consecuencia que son los Estados quienes crean las normas y les dan aplicación en sus relaciones mutuas, sin perjuicio de que, en determinados supuestos, exista el recurso a órganos internacionales. La ausencia de una autoridad central encargada de la aplicación de dichas normas conlleva que sean los propios Estados los encargados de vigilar y controlar, en principio, la aplicación. En definitiva, la descentralización del ordenamiento jurídico internacional queda plasmada en que "no existe, en primer lugar, un órgano legislativo universal encargado de elaborar las normas generales que sean de aplicación a la sociedad internacional en su conjunto... No existe tampoco, en el DIP, un poder judicial 'central' y general como en el derecho interno... No existe, en fin, en el DIP un poder ejecutivo universal que haga cumplir las normas internacionales". ${ }^{51}$

La actual universalización del DIP, que es reflejo de las transformaciones operadas en la sociedad internacional, viene referida al alcance o ámbito de aplicación de sus normas. ${ }^{52}$ El universalismo expresa una tendencia hacia una normatividad aplicable a todos los Estados que componen la sociedad internacional y se manifiesta en la existencia de normas internacionales universales o generales: por derecho internacional general se entienden aquellas normas internacionales que se aplican universalmente a todos los Estados.

Una vez indicadas las características particulares del DIP, en tanto que ordenamiento jurídico internacional, procede señalar respecto de éste

51 Gutiérrez Espada, C., Derecho internacional público, Madrid, Trotta, 1995, pp. 50, 51 y 52.

52 Wengler, W., "La crise de l'unité de l'ordre juridique international", Mélanges offerts à Ch. Rousseau. La Communauté internationale, París, Pédone, 1974, pp. 329 y ss. 
las singularidades del DCE. Así, desde la óptica del DCE, frente a la relatividad cabe sostener la homogeneidad, frente a la descentralización la elevada centralización institucional en los procedimientos de elaboración normativa y, en menor medida, la de los mecanismos de aplicación normativa $\mathrm{y}$, finalmente, frente a la universalidad el particularismo. Advertir que, por cuestiones de economía procesal, en relación a la última cuestión enunciada nos remitimos a lo tratado acerca del particularismo jurídico del ordenamiento jurídico comunitario.

La homogeneidad del DCE viene determinada por varias circunstancias, principalmente por los tratados constitutivos y los diferentes actos normativos elaborados en el seno de las instituciones comunitarias. Además, la labor del TJCE permite asegurar la unidad de interpretación y aplicación del DCE en el conjunto de los Estados miembros, ya que a través de la cuestión prejudicial de interpretación proporciona la interpretación realmente auténtica del DCE; ${ }^{53}$ asimismo, mediante el recurso de anulación y la cuestión prejudicial de validez, el TJCE revisa la conformidad de los actos normativos de carácter general de las instituciones con los tratados constitutivos. ${ }^{54}$ Obviamente, la primacía y el efecto directo del DCE contribuyen en gran medida a que el cuerpo normativo comunitario sea homogéneo y uniforme en su aplicación en el conjunto de la UE. La concurrencia de estas circunstancias posibilita que el DCE, al contrario que el DIP, no venga caracterizado por el relativismo.

Los procedimientos de producción normativa comunitaria dispuestos por los tratados constitutivos revisten un elevado grado de centralización institucional en comparación con la descentralización propia del DIP. Como afirma Louis, ${ }^{55}$ el derecho derivado constituye un original proceso de creación normativa, ya que se trata de "un derecho legislado, es decir, un cuerpo de normas segregado por la misma comunidad, de manera casi autónoma, a pesar de su carácter derivado de los tratados, tomado pues en aplicación y para la aplicación de éstos". ${ }^{56}$

De los mecanismos de aplicación del DCE cabe advertir que, al contrario que en un supuesto de producción normativa, no se puede hablar

53 Isaac, G., Manual de derecho comunitario general, Barcelona, Ariel, 1997, p. 263.

54 Rodríguez Iglesias, G., "El Tribunal de Justicia de las Comunidades Europeas", El derecho comunitario europeo y su aplicación judicial, Madrid, 1993, p. 384.

55 Louis, J., El ordenamiento jurídico comunitario, Bruselas, Comisión de las Comunidades Europeas, 1987, p. 63.

56 Isaac, G., Manual de derecho comunitario general, Barcelona, Ariel, 1997, p. 171. 
de centralización, pues la ejecución de las normas comunitarias en sus territorios se otorga a los Estados miembros. Ahora bien, al respecto, el artículo 10 del TCE dispone el deber de colaboración de los Estados miembros en la aplicación del DCE, pues "adoptarán todas las medidas generales o particulares apropiadas para asegurar el cumplimiento de las obligaciones derivadas del presente tratado o resultantes de los actos de las instituciones de la comunidad. Facilitarán a esta última el cumplimiento de su misión".

El control de la aplicación de las normas comunitarias por los Estados miembros en sus territorios es ejercitado por el TJCE a través del recurso de incumplimiento (artículos 226 a 228 TCE).

\section{LA INCIDENCIA DEL DERECHO COMUNITARIO EUROPEO EN EL DERECHO INTERNACIONAL}

\section{En el ámbito de las organizaciones internacionales. Técnicas de cooperación}

Históricamente, el origen de la idea o fenómeno organización internacional responde, por un lado, a una aspiración general a la paz y al progreso de las relaciones pacíficas en el seno de la sociedad internacional y, por otro, a una serie de necesidades específicas en diferentes ámbitos y que son comunes a todos los Estados, tales como el económico, científico, social, etcétera. Desde un prisma sociológico puede sostenerse que las organizaciones internacionales se presentan como un fenómeno tendente a compensar la falta de cohesión social existente en la sociedad internacional y la ausencia de una autoridad central. En este sentido, las organizaciones internacionales son la proyección institucional de la estructura de yuxtaposición de Estados, dependiendo su iniciativa y actuación de la voluntad de los Estados miembros ${ }^{57} \mathrm{y}$, en consecuencia, el fenómeno organización es un factor de dinamización encaminado a paliar la falta de institucionalización existente en la sociedad internacional.

En este contexto, los Tratados CECA, de 18 de abril de 1951, CEE y CEEA de 25 de marzo de 1957 crearon, respectivamente, la Comunidad Europea del Carbón y del Acero (CECA), la Comunidad Económica Eu- 
ropea (CEE) y la Comunidad Europea de la Energía Atómica (CEEA) y, después del llamado Tratado de la Unión, de 9 de febrero de 1992, las citadas comunidades han pasado a integrar la UE. En consecuencia, a partir de este momento, al igual que el resto de las organizaciones internacionales, las comunidades europeas adquieren el status de sujeto de DIP con personalidad jurídica internacional limitada o secundaria —en tanto que han sido creadas por los Estados, sujetos internacionales originarios, mediante un instrumento convencional internacional- y base funcio$n_{a}{ }^{58}$ — a diferencia de los Estados que son sujetos de base territorial, no tienen territorio $\mathrm{y}$, en consecuencia, deberán ejercer sus funciones en el territorio de los Estados-.

Sin embargo, desde su creación, las comunidades europeas han constituido un hito en la materia, pues, desde el punto de vista de los métodos de cooperación, se trata de una organización internacional de integración, incluso ha sido calificada como supranacional, en tanto que supone el esfuerzo de cooperación más intenso existente en el ámbito del fenómeno de la organización internacional. Las organizaciones de integración tienen como objeto la unificación — al menos parcial y sectorial- de los territorios y de las poblaciones de los Estados que las componen, en tanto que disponen de poderes de tipo estatal (legislación, jurisdicción...) que ejercen sobre el territorio de los Estados y sobre las personas que se encuentran en ellos.

En consecuencia, la Comunidad Europea se configura como un nuevo modelo de organización internacional frente al modelo tradicional, pues, en tanto que organización internacional, la Comunidad Europea muestra rasgos específicos que la alejan de las organizaciones internacionales existente en el momento de su creación. Por otra parte, no puede obviarse que el modelo de organización internacional iniciado por la Comunidad Europea ha sido seguido por otras organizaciones, tales como la Comunidad Andina, el Mercosur y la NAFTA.

En todo caso, señalar que, al igual que ocurriera con otras organizaciones internacionales creadas con anterioridad — entidades distintas y diferenciadas de los Estados-, la aparición en el contexto internacional de la Comunidad Europea, si bien no ha supuesto una quiebra ni un desplazamiento de la dimensión interestatal de la sociedad internacional, sí 
ha modernizado y adaptado dicho sistema a las nuevas circunstancias, pues:

El Estado sigue siendo la llave maestra de las acciones fundamentales que pueden ser emprendidas, pero no podemos olvidar el papel creciente, irreversible y generalmente positivo, de las organizaciones internacionales intergubernamentales a la hora de imaginar soluciones, de poner en común esfuerzos y medios. El individuo, aislado o en grupos sociales, incluso transnacionales, sigue estando en realidad, en el umbral del DIP, en imagen que gustaba utilizar al maestro Miaja de la Muela. Pero no se puede desconocer la presión social que realizan para mejorar el contenido del DIP, para que éste se desarrolle por el buen camino, en aras de la solución de los problemas contemporáneos que superan las formas clásicas de organización política, la estatal y la local (o regional). ${ }^{59}$

\section{En el ámbito de las competencias de las organizaciones internacionales}

En el ámbito de la Comunidad Europea, las funciones que tiene atribuidas exceden en mucho a las atribuciones conferidas a las organizaciones clásicas u organizaciones de cooperación, esto es, al tratarse la Comunidad Europea de una organización de integración, se alimenta de poderes de los Estados miembros. Los Estados firmantes no estaban creando obligaciones mutuas entre ellos simplemente, ${ }^{60}$ sino que iban más allá, estaban limitando sus derechos soberanos y transfiriéndolos a instituciones sobre las que no tenían un control directo. ${ }^{61}$ En otras palabras, las transferencias de competencias estatales a la Comunidad Europea van más allá de los supuestos normales de transferencia de competencias a una organización, pues determinadas materias de competencia estatal pasan a estar regulados por la propia Comunidad Europea y, de

59 Bernad Álvarez de Eulate, M., El derecho internacional en la nueva situación, Zaragoza, Real Instituto de Estudios Europeos, 1995, p. 29.

60 Asunto Van Gend en Loos (As. 26/62), Rep. TJCE, 1963, pp. 1-12.

61 Mathijsen, P., Guía del derecho de la Comunidad Europea, Madrid, Banco Exterior de España, 1987, p. 43. El TJCE ha declarado que "al constituir una Comunidad de duración ilimitada, dotada de instituciones propias, de personalidad, de capacidad jurídica, de capacidad de representación internacional, y más particularmente de poderes reales nacidos de una limitación de competencia o de una transferencia de atribuciones de los Estados de la Comunidad, éstos han limitado, aunque en ámbitos restringidos, sus derechos soberanos, y han creado así un cuerpo de derecho aplicable a sus nacionales y a ellos mismos" (Asunto Costa $v$ ENEL, Rep. TJCE 1964, p. 1143). 
esta forma, dicha organización internacional constituye una categoría especial dentro del fenómeno de la organización internacional.

La atribución de competencias a la Comunidad Europea conlleva una limitación correlativa de poderes de los Estados miembros y, por tanto, una limitación de su soberanía: "las CCEE tienen atribuidas funciones que comúnmente son ejercitadas por los sujetos estatales y que, con anterioridad, correspondían naturalmente a sus Estados miembros, con la consecuencia de que en los ámbitos de su competencia se produce una sustitución de los Estados en beneficio de las CCEE". ${ }^{62}$ En este sentido, a través de los tratados constitutivos, los Estados miembros han atribuido a las instituciones comunitarias una serie de competencias que comporta el desplazamiento en el ejercicio de las mismas por los Estados miembros. Así, en la esfera de las materias sobre las que la Comunidad Europea tiene competencias exclusivas, los Estados miembros han renunciado a todo ejercicio de las mismas. En este sentido, la aparición de las organizaciones internacionales "suponen un ataque funcional, por elevación, a la soberanía de los Estados". ${ }^{63}$

\section{En el ámbito de los procedimientos de creación de normas}

Atendiendo a la estructura de la sociedad internacional contemporánea, no existe un procedimiento institucionalizado de creación de normas internacionales, esto es, en el ámbito del DIP no existe un legislador supraestatal y, por esto, el Estado se configura como "legislador internacional". Los Estados son los principales creadores de las normas internacionales. El DIP es creado y desarrollado progresivamente por los Estados $\mathrm{y}$, por consiguiente, el consentimiento estatal, expresión jurídica de la soberanía, se presenta como de vital importancia en la elaboración del mencionado derecho ${ }^{64}$ en tanto que es considerado como la fuente material del DIP.

Las normas internacionales creadas por los Estados son el resultado de un proceso de creación jurídica en el cual se traduce su consentimiento acerca de la necesidad de regular una determinada materia y de dotar

62 Mangas Martin, A y Liñan Nogueras, D., Instituciones y derecho de la Unión Europea, Madrid, McGraw-Hill, 1999, p. 326.

63 Rodríguez Carrión, A., El derecho internacional en el umbral del siglo XXI, Universidad de Málaga, 1999, p. 18.

64 Al respecto, la sentencia relativa al CPJI, “Asunto Lotus”, Serie A, núm. 10, p. 18. 
de un contenido concreto a dicha regulación; proceso cuyo punto final se sitúa en la cristalización del acuerdo sobre la existencia y el contenido de la norma. Dicho de otro modo, en el ámbito del DIP, el consentimiento del Estado se presenta como una función de carácter fundamental en el proceso de creación y formación de sus normas, ya que en el DIP, el origen real y último de sus normas descansa, fundamentalmente, en el consentimiento de los Estados, y eventualmente en otros sujetos de DIP.

El planteamiento desarrollado en el párrafo precedente necesita de una ulterior puntualización dado que el proceso de creación de normas trasciende de la base individual del consentimiento del Estado para constituir la expresión del grupo social en su conjunto, o de grupos particulares de Estados. Por esto, ante tal situación, debe sostenerse que mientras el consentimiento estatal es el punto inicial y necesario del proceso de creación de normas, no es, en modo alguno, el término final. En el proceso de desarrollo del derecho, el término final está constituido por el consentimiento ad idem de una pluralidad de sujetos internacionales; con lo cual se opera la transformación de la pluralidad de consentimientos individuales en un consensus de los Estados. Por consiguiente, en la actualidad únicamente es posible que surja una norma internacional mediando el previo consentimiento del Estado individualmente considerado como punto de partida del proceso normativo, seguido más tarde por una suma suficiente de consentimientos individuales de los Estados participantes en este proceso, en tanto que prueba de la presencia de un consensus generalis o acuerdo general del grupo de Estados interesados como término final del proceso.

Una vez realizado el planteamiento anterior, cabe concluir que la producción normativa en el DIP se realiza a través del tratado internacional y la costumbre internacional que, si bien son dos procedimientos primarios y autónomos, se caracterizan por ser el primero eminentemente formal y el segundo espontáneo. A estos dos procedimientos deben añadirse los principios generales del derecho, que son una categoría común al DIP y a los derechos internos de los Estados.

Una vez establecida la situación y el procedimiento tradicional de creación de normas jurídicas internacionales en sede iusinternacionalista procede indicar el procedimiento de creación normativa mediante resoluciones externas de la Comunidad Europea. En tanto que organización internacional de integración, dicha comunidad, a cuyas instituciones los Estados miembros han transferido competencias tradicionalmente reser- 
vadas a la esfera exclusiva de su soberanía, puede adoptar resoluciones obligatorias en todos sus términos y directamente aplicables, resoluciones obligatorias en cuanto al resultado y resoluciones desprovistas de obligatoriedad.

El derecho comunitario derivado o normas derivadas se cualifican esencialmente por tratarse de un conjunto de modos de instrumentalización jurídica con fundamento en la norma constitutiva. ${ }^{65}$ Como señala Díez-Hochleitner, "el derecho derivado traduce el ejercicio de un amplio poder normativo por las instituciones, a través de procedimientos complejos que... trascienden con mucho a los esquemas de la cooperación intergubernamental. Por otra parte, los actos que los integran se dirigen no sólo a los Estados miembros sino igualmente a los particulares, configurándose además como actos que reclaman en muchos casos una aplicabilidad directa. Es difícil encontrar precedentes de este fenómeno que, por otra parte, sirve de inspiración a nuevas organizaciones de integración". 66

Primero, el artículo 249 del Tratado de la CE dispone que "el reglamento tendrá un alcance general. Será obligatorio en todos sus elementos y directamente aplicable en cada Estado miembro". El contenido y la forma del reglamento son obligatorios para los Estados miembros y, de esta manera, como indica Rodríguez Carrión, ${ }^{67}$ el citado instrumento es lo más próximo al significado que los actos legislativos tienen en los derechos internos, derechos que suelen caracterizarse por una homogeneidad que es aún escasa en el orden internacional. Por consiguiente, como la ley en los ordenamientos jurídicos internos, el reglamento tiene alcance general, es obligatorio en todos sus extremos y directamente aplicable en cada Estado miembro de la UE. No necesita, pues, ulterior desarrollo normativo interno. Y, segundo, el citado precepto establece que "la directiva obligará al Estado miembro destinatario en cuanto al resultado que deba conseguirse, dejando, sin embargo, a las autoridades nacionales la elección de la forma y de los medios". Al contrario que el reglamento,

65 Mangas Martin, A. y Liñan Nogueras, D., Instituciones y derecho de la Unión Europea, Madrid, McGraw-Hill, 1999, p. 169.

66 Díez-Hochleitner, J., "La interdependencia entre el derecho internacional y el derecho de la Unión Europea”, Cursos de derecho internacional de Vitoria Gasteiz (1998), Madrid, Tecnos, 1999, p. 80 .

67 Rodríguez Carrión, A., Lecciones de derecho internacional público, Madrid, Tecnos, 2002, p. 241. 
el alcance de la directiva no es general. Como puede advertirse, en este supuesto la obligación jurídica del Estado miembro se satisface con la consecución del resultado, sin que se disponga una obligación de comportamiento para la obtención de dicho resultado, es decir, los Estados miembros disponen de plena libertad a la hora de elegir el acto normativo de transposición de la directiva (ley, reglamento, decreto, etcétera). Además de los reglamentos y las directivas, el artículo 249 del TCE contempla las decisiones, las recomendaciones y los dictámenes.

\section{En el ámbito de la incorporación del derecho comunitario europeo a los ordenamientos jurídicos de los Estados miembros}

Un Estado que ha contraído válidamente obligaciones internacionales está obligado a introducir en su legislación las modificaciones que sean necesarias para asegurar la ejecución de los compromisos asumidos, ${ }^{68}$ pero además no puede invocar respecto de otro Estado su propia Constitución para sustraerse a las obligaciones que le impone el DIP. En atención a las disposiciones contenidas en los ordenamientos jurídicos internos sobre la recepción de las normas convencionales internacionales, cabe dividirlos en ordenamientos jurídicos dualistas y monistas. En los sistemas dualistas no cabe la posibilidad de que los órganos internos apliquen los tratados internacionales mientras que no hayan sido transformados mediante un acto normativo interno, ya que las normas internacionales son irrelevantes en los ordenamientos jurídicos internos. Esta postura tiene su razón de ser en el hecho de que el DIP y los derechos internos son concebidos como ordenamientos jurídicos separados e independientes. Desde esta perspectiva, "una norma internacional incorporada a un ordenamiento interno lo será en virtud de algún mandato legal establecido en el ordenamiento interno, pero al incorporarse pierde su naturaleza internacional para convertirse en norma interna. En realidad, la norma será internacional por su origen, pero plenamente interna en cuanto a su naturaleza y aplicabilidad". ${ }^{69} \mathrm{El}$ sistema monista, al contrario que el dualista, proclama la unidad de todos los ordenamientos jurídicos, en tanto que expresiones diferenciadas del fenómeno jurídico, y, por tanto, los tratados internacionales son parte del ordenamiento jurídico inter-

68 CPJI, Asunto del intercambio de poblaciones griegas y turcas, Serie B, núm. 10, p. 20.

69 Rodríguez Carrión, A., Lecciones de derecho internacional público, Tecnos, Madrid, 2002, p. 267. 
no, una vez obligatorios en el ámbito internacional, pues no puede existir "una disociación entre la validez internacional de la norma y la validez interna". ${ }^{70}$

El DIP no se pronuncia ni por el postulado dualista ni monista, sino que deja tal cuestión a los derechos internos. Sobre la base dispuesta por los ordenamientos jurídicos internos, si se trata de un sistema dualista o monista, cabe distinguir los regímenes de recepción especial y automática. La recepción especial (sistema dualista) conlleva la exigencia de una previa transformación del tratado, mediante un acto formal de producción normativa interna (por ejemplo, ley, decreto, reglamento, orden), para que vincule en el orden interno. La recepción automática (sistema monista), por el contrario, supone la incorporación inmediata del tratado en el ordenamiento interno (es parte integrante) una vez que ha entrado en vigor y es internacionalmente obligatorio.

La generalidad de las Constituciones estatales apenas contienen menciones sobre la incorporación al ordenamiento jurídico interno de las normas consuetudinarias internacionales. ${ }^{71}$ ¿Qué ocurre en los Estados cuyos ordenamientos jurídicos guardan silencio al respecto? La costumbre internacional surge de una práctica general, constante y uniforme (elemento material), acompañada de la convicción de obrar conforme a derecho (elemento espiritual) y, en consecuencia, es derecho no escrito. Esta naturaleza de las normas consuetudinarias explica que su recepción en el ordenamiento jurídico interno de los Estados se realice sin necesidad de ningún acto formal de incorporación. Señala Mangas Martín que "la doctrina iusinternacionalista europea trata de explicar, ante casos similares, la ausencia de una formal recepción del derecho internacional general por la existencia de una norma tácita de adopción automática de las normas consuetudinarias en todo orden jurídico interno". ${ }^{72}$ Así pues, en los ordenamientos jurídicos internos que guardan silencio, las normas consuetudinarias se incorporan a ellos desde el momento de su forma-

70 Mangas Martín, A., "La recepción del derecho internacional por los ordenamientos internos", Instituciones de derecho internacional público, Madrid, Tecnos, 2003, p. 221.

71 Al respecto, Visscher, P. de, "Les tendences internationales des constitutions modernes", $R C A D I$, t. 80, 1952, p. 520; Cassese, A., "Modern constitutions and international law", $R C A D I$, t. 192, 1985, p. 369.

72 Mangas Martín, A., "La recepción del derecho internacional por los ordenamientos internos", Instituciones de derecho internacional público, Madrid, Tecnos, 2003, p. 196. 
ción, salvo oposición manifiesta, las cuales son aplicadas por los órganos judiciales internos.

La interrelación entre el DCE y los ordenamientos jurídicos de los Estados miembros ofrece características nuevas y distintas de la tradicional relación entre el DIP y los derechos internos. Así, el DCE es directamente aplicable en la esfera interna de los Estados miembros sin necesidad de ningún acto de recepción por parte de éstos: las normas jurídicas comunitarias no sólo obligan a los órganos comunitarios y a los Estados miembros, sino también a los ciudadanos de esos Estados miembros, sin necesidad de ningún acto de incorporación estatal. ${ }^{73}$ El reglamento comunitario se incorpora en los ordenamientos jurídicos nacionales a partir del momento de su publicación en el Diario Oficial de la Comunidad Europea (artículo 254 TCE), sin necesidad de un acto de recepción interno por parte de los Estados destinatarios. Por otra parte, la directiva comunitaria, a partir del momento de su notificación a los Estados miembros, acompañada de la publicación en el Diario Oficial (artículo 254 $\mathrm{TCE}$ ), se incorpora en los ordenamientos jurídicos internos.

\section{En el ámbito del derecho de los tratados}

\section{A. Tratados celebrados por los Estados miembros} de la Unión Europea con terceros Estados

a. Tratados anteriores a la entrada en vigor del Tratado de la Comunidad Europea

El artículo 307 del TCE señala que "las disposiciones del presente tratado no afectarán a los derechos y obligaciones que resulten de convenios celebrados, con anterioridad al 1o. de enero de 1958 o, para los Estados que se hayan adherido, con anterioridad a la fecha de su adhesión, entre uno o varios Estados miembros, por una parte, y uno o varios terceros Estados, por otra". Seguidamente, la disposición transcrita señala que "en la medida en que tales convenios sean incompatibles con el presente tratado, el Estado o los Estados miembros de que se trate recurrirán a todos los medios apropiados para eliminar las incompatibilidades

73 Medina, M., La Comunidad Europea y sus principios constitucionales, Madrid, Tecnos, 1974, p. 112. 
que se hayan observado". El precepto transcrito, como advierte Louis, es objeto de polémica doctrinal pues, "para unos, el artículo... no tiene por efecto transferir a la comunidad los compromisos contraídos anteriormente por los Estados. Para otros, esta disposición consagra un efecto de sustitución o sucesión de la comunidad a sus Estados miembros, en lo referente a los compromisos susceptibles de influir en el ejercicio de competencias atribuidas a la comunidad". ${ }^{74}$ Como puede observarse, la cuestión relativa a respetar las obligaciones internacionalmente adquiridas por un Estado miembro y los derechos de los terceros Estados, se presenta problemática con relación a su alcance en el DCE, esto es, la cuestión a dilucidar es si estos tratados vinculan a la Comunidad Europea y, en su caso, cuál es su alcance. La respuesta a esta pregunta pasa, siguiendo el planteamiento elaborado por Mangas Martin y Liñán Nogueras, ${ }^{75}$ por establecer la distinción entre los convenios que no afectan a la competencia comunitaria y los convenios que afectan a ámbitos de competencia comunitaria.

En cuanto a los convenios que no afectan a competencias atribuidas a la Comunidad Europea, dicha comunidad queda vinculada y obligada a respetar dicho tratado internacional (por ejemplo, un tratado en materia de delimitación de fronteras internacionales entre dos Estados, tratados en materia de ríos internacionales, etcétera).

Más compleja es la cuestión relativa a tratados que afectan esferas de competencia comunitaria, pues el nudo gordiano se centra en establecer si la Comunidad Europea sustituye al Estado miembro en sus obligaciones con respecto a terceros Estados. Al respecto hay que traer varias sentencias del TJCE: 1) En la Sentencia de 12 de diciembre de 1972, relativa al asunto International Fruit Company, ${ }^{76}$ el TJCE consideró que la Comunidad Europea sustituía a los Estados miembros y, en concreto, declaró el carácter obligatorio del GATT para la Comunidad Europea. El TJCE fundamentó su decisión en el artículo 307 del Tratado de la CE [antiguo artículo 234]. 2) En la Sentencia de 2 de agosto de 1993, sobre el asunto Levy, ${ }^{77}$ el TJCE declaró la no sustitución de los Estados miem-

74 Louis, J., El ordenamiento jurídico comunitario, Bruselas, Comisión de las Comunidades Europeas, 1987, p. 83.

75 Mangas Martin, A. y Liñan Nogueras, D., Instituciones y derecho de la Unión Europea, Madrid, McGraw-Hill, 1999, p. 192.

76 Rep. TJCE 1972, p. 1219.

77 Rep. TJCE 1993, p. 4287. 
bros por la Comunidad Europea y se mantienen las obligaciones contraídas con terceros Estados para el Estado miembro. 3) En la Sentencia de 14 de octubre de 1980, relativa al asunto Burgoa, ${ }^{78}$ el TJCE declaró que el referido artículo debe ser interpretado en el sentido de que la aplicación del tratado no afecta ni al respeto debido a los derechos de los Estados terceros resultantes de un convenio concluido con un Estado miembro con anterioridad a la entrada en vigor del tratado o, en su caso, a la adhesión del Estado miembro, ni a la observancia por parte de este mismo Estado de las obligaciones que resultan del convenio y que, consecuentemente, las instituciones de la comunidad están obligadas a no obstaculizar la ejecución de dichas obligaciones por el Estado miembro en cuestión. Así, dicha obligación no tiene por efecto vincular a la Comunidad Europea con respecto al Estado tercero interesado.

En consecuencia, al tenor de las dos sentencias últimas, como ha señalado Louis, se mantiene el respeto de las obligaciones contraídas con terceros Estados y para el Estado en cuestión se habilita la oponibilidad frente a las instituciones comunitarias: "la solución de la simple oponibilidad tiene la ventaja de que no paraliza a la comunidad en el ejercicio de sus competencias y evita que el conjunto de los Estados miembros tengan que asumir obligaciones que no todos han suscrito". ${ }^{79}$

\section{$b$. Tratados celebrados con posterioridad a la entrada en vigor del Tratado de la Comunidad Europea}

Otra cuestión es la relativa a los tratados internacionales celebrados con posterioridad a la entrada en vigor del Tratado de la CE. En principio, los tratados celebrados por Estados miembros sobre materias cuya competencia es de la Comunidad Europea no son válidos respecto al DCE. Por el contrario, los tratados concluidos por los Estados miembros en materias cuya competencia no está atribuida a la Comunidad Europea sí son válidos respecto del DCE. Ahora bien, si posteriormente a su celebración es atribuida la competencia en tal materia a la comunidad, las disposiciones comunitarias posteriores al tratado tendrán prioridad. En todo caso, la cuestión tratada es a nivel de hipótesis, pues como advirtió Isaac, "sigue abierto el problema de saber si la comunidad estaría vincu-

78 Rep. TJCE 1980, p. 2787.

79 Louis, J., El ordenamiento jurídico comunitario, Bruselas, Comisión de las Comunidades Europeas, 1987, p. 84. 
lada por los acuerdos celebrados por los Estados miembros posteriormente a la entrada en vigor del tratado $\mathrm{CEE}$, en los ámbitos que pertenecen a su competencia residual o transitoria". ${ }^{80}$

\section{B. Los tratados concluidos por la Comunidad Europea} con terceros Estados

La celebración de tratados internacionales es una actuación básica para el ejercicio de las competencias comunitarias en materia de relaciones exteriores. La capacidad de conclusión de acuerdos en el Tratado de la CE permite la celebración de tratados por parte de la comunidad con terceros Estados, por un lado, y la celebración de tratados mixtos, esto es, aquellos concluidos con terceros Estados en los que participan de una forma conjunta la comunidad y sus Estados miembros, por otro. El artículo 133 del Tratado de la CE contempla los llamados acuerdos comerciales, mientras que en el artículo 310 contiene los denominados acuerdos de asociación.

El Tratado de la CEEA dispone en los artículos 101 a 103 la capacidad de conclusión de acuerdos en el ámbito de esta comunidad. En virtud del artículo 101, en el ámbito de su competencia, esta comunidad podrá obligarse, mediante la celebración de acuerdos o convenios con un tercer Estado, una organización internacional o un nacional de un tercer Estado. El artículo 102 prevé los llamados acuerdos mixtos y el artículo 103 contempla la posibilidad de que los Estados miembros concluyan acuerdos internacionales con otros sujetos.

En cuanto a los tratados concluidos por la Comunidad Europea con terceros Estados, atendiendo a la jurisprudencia del TJCE - especialmente en la Sentencia de 30 de septiembre de 1987, relativa al asunto Demirel (As. 12/86) — ${ }^{81}$ se desprende que los tratados concluidos por la Comunidad Europea con terceros Estados vinculan a los Estados miembros en tanto que dichos tratados se incorporan en el ordenamiento jurídico comunitario, es decir, que la vinculación de los Estados miembros a dichos tratados no viene determinada por el DIP, sino por el DCE. La consecuencia que se colige del planteamiento anterior es que, en caso de incumplimiento por parte de la Comunidad Europea de un tratado con-

80 Isaac, G., Manual de derecho comunitario general, Barcelona, Ariel, 1997, p. 150.

81 Rep. TJCE 1988, pp. 3719 y ss. 
cluido por ella con un tercer Estado, la responsabilidad internacional generada alcanzará solamente a la Comunidad Europea, quedando al margen los Estados miembros. En consecuencia, la Comunidad Europea deberá responder del incumplimiento ante el Estado tercero.

Por lo que respecta a los acuerdos mixtos, a nivel práctico, la cuestión se presenta compleja como consecuencia de la distribución de competencias entre la Comunidad Europea y los Estados miembros. Como señalan Mangas Martin y Liñan Nogueras, esta "cuestión sigue siendo un sector jurídico oscuro en las relaciones exteriores de las CCEE". ${ }^{82} \mathrm{En}$ todo caso, cabe señalar las siguientes posiciones: 1) Que el propio acuerdo mixto contemple las obligaciones que corresponden a la Comunidad Europea y las obligaciones que atañen a los Estados miembros, es decir, que se determine la esfera competencial de cada parte y, de esta manera, la responsabilidad en caso de incumplimiento recaerá sobre el que tuviere competencia en la materia: Comunidad Europea o Estado miembro; y 2) En el supuesto de que el acuerdo mixto no contemple la circunstancia anterior, la jurisprudencia del $\mathrm{TJCE}^{83}$ entiende que se está en presencia de una responsabilidad conjunta de carácter solidario: la Comunidad Europea y los Estados miembros de forma conjunta son responsables internacionalmente del incumplimiento.

\section{En el ámbito de la interpretación}

Una vez determinada la existencia de la norma internacional, la interpretación de la misma es una actividad necesaria para su aplicación: toda aplicación de una norma internacional requiere una previa interpretación. Así, la interpretación adquiere toda su magnitud en la esfera de la aplicación de la norma: ${ }^{84}$ la función interpretativa es esencial, necesaria al orden jurídico. No es posible cumplir ni aplicar ninguna norma, como no sea sobre la base de una interpretación. En el ámbito del ordenamiento jurídico comunitario, el TJCE es el órgano competente para interpretar el DCE: tiene competencia exclusiva para la interpretación del DCE,

82 Mangas Martin, A. y Liñan Nogueras, D., Instituciones y derecho de la Unión Europea, McGraw-Hill, Madrid, 1999, p. 329.

83 Véase la sentencia de 2 de marzo de 1994 relativa al Asunto Parlamento Europeo vs. Consejo (As. C-316-91), Rep. TJCE, pp. 625 y ss.

84 Larenz, K., Metodología de la ciencia del derecho, Barcelona, Ariel, 1980, pp. 192 y ss.; y Wroblewski, J., Constitución y teoría general de la interpretación jurídica, Madrid, Civitas, 1985, pp. 22 y ss. 
siendo irrelevante la interpretación que sobre este derecho realicen los órganos de los Estados miembros, a sensu contrario, el TJCE no puede interpretar al derecho nacional. Así, éste órgano jurisdiccional y el Tribunal de Primera Instancia garantizarán, en el marco de sus respectivas competencias y a través de los procedimientos dispuestos en el DCE (procedimiento contencioso entre los Estados y cuestión prejudicial a petición de los órganos judiciales de los Estados miembros), el respeto del derecho en la interpretación y aplicación del DCE. Por consiguiente, la circunstancia apuntada conlleva una nueva visión en los procedimientos tradicionales de interpretación en sede iusinternacionalista.

Respecto a los criterios de interpretación sentados por el TJCE debe señalarse que no hay innovaciones radicales, pues la interpretación del DCE es llevada a cabo incorporando criterios de interpretación en los que todos los Estados miembros son partes, es decir, el Convenio de Viena sobre el Derecho de los Tratados de 1969 y el Convenio de Viena sobre el Derecho de los Tratados entre Estados y Organizaciones Internacionales o entre Organizaciones Internacionales de 1986.

\section{En el ámbito del derecho de legación}

En tanto que sujetos de DIP, las organizaciones internacionales disfrutan del derecho de legación activa y pasiva; así, la facultad de enviar o recibir representantes diplomáticos se presenta como una manifestación de su personalidad jurídico internacional. Los Tratados Constitutivos de la Comunidad Europea no contienen ninguna disposición sobre el derecho de legación pasivo y activo. No obstante, el artículo 17 del Protocolo sobre los Privilegios y las Inmunidades de la Comunidad Europea, de 8 de abril de 1965, estipula que "el Estado miembro en cuyo territorio esté situada la sede de las comunidades concederá a las misiones de terceros Estados acreditadas ante las comunidades las inmunidades y privilegios diplomáticos habituales" y, sobre la base de esta disposición, se ha fundamentado una práctica en materia de legación pasiva en la que la comisión y el consejo han definido las competencias respectivas y los procedimientos en relación con la acreditación de misiones y representaciones de terceros ante la Comunidad Europea: una vez los Estados miembros han prestado unánimemente su consentimiento para el establecimiento de la misión y la presentación de las cartas credenciales, de forma separada, en el mismo día, al presidente del consejo y al presidente de la comisión. 
En cuanto al derecho de legación activo, cabe señalar, en un primer momento, el establecimiento de oficinas o delegaciones exteriores por parte de la comisión, siempre que el tercer Estado o la organización internacional correspondiente consintieran en ello. En la actualidad, la representación es ejercitada por las delegaciones y oficinas exteriores de la comisión y por las misiones diplomáticas de los Estados miembros y, de forma particular, por la misión diplomática del Estado al que corresponde la Presidencia del consejo. El establecimiento de las delegaciones se lleva a término mediante acuerdos con terceros Estados u organizaciones internacionales.

\section{En el ámbito de la protección diplomática}

El ejercicio de la protección diplomática requiere la concurrencia de las condiciones de la nacionalidad de la reclamación; el agotamiento de los recursos en el orden jurídico interno y la conducta correcta de la persona perjudicada. ${ }^{85}$ Respecto a la primera condición, la persona lesionada debe ser nacional del Estado que pretende ejercitarla, pues sólo el vínculo de nacionalidad entre el Estado y el individuo le da a aquél el derecho a la protección diplomática. ${ }^{86}$ Así pues, atendiendo a una regla consuetudinaria general, un Estado únicamente puede ejercer la protección diplomática de sus nacionales. Sin embargo, cabe que existan acuerdos particulares ("en ausencia de acuerdos particulares, es el vínculo de la nacionalidad...”). ${ }^{87}$ La existencia de dichos acuerdos permite que un Estado, del cual la persona perjudicada no es nacional, ejerza la protección diplomática. En este sentido, el Tratado de la UE, de 19 de febrero de 1992, contempla la posibilidad de que la protección diplomática, relativa a un nacional de algún Estado comunitario (ciudadanía comunitaria), sea ejercitada por un Estado comunitario distinto al de su nacionalidad, si el Estado del que es nacional no posee representación diplomática en el tercer Estado (artículo 20). Ahora bien:

A la vista de las características de la institución, la posibilidad de que cualquier Estado de la Unión inicie la acción de protección de un ciudadano de

85 Salmon, J., "Des 'mains propres' comme condition de recevabilité des réclamations internationales", AFDI, 1964, pp. 225 y ss.

86 CPJI, Asunto del ferrocarril Panevezys-Saldutiskis, Serie A/B, núm. 76, pp. 15 y 16.

87 Ibidem, pp. 15 y 16. 
la Unión que no sea nacional suyo depende de la aceptación de la acción por parte del Estado reclamado, por lo que habrá que observar si en los tratados de la Unión con terceros Estados, como ya ha empezado a ocurrir con ciertos acuerdos pesqueros con países africanos, se incluye o no una cláusula en tal sentido. Quizás, en última instancia, a los autores del citado artículo les preocupaba más la asistencia consular y diplomática de los ciudadanos de la Unión en el exterior que la protección ante terceros Estados. Y es que, en efecto, en el trascrito artículo se trata más de una protección diplomática en sentido amplio, esto es, la acción de protección de un Estado por los sucesos que puedan ocurrirle a sus nacionales en el extranjero sin que se haya producido una acción ilícita por parte del Estado en cuyo territorio se encuentren, más que una protección diplomática en el sentido estricto de la institución a la que nos venimos refiriendo. ${ }^{88}$

\section{CONSIDERACIONES FINALES}

1. El DCE, en tanto que ordenamiento jurídico de la UE, es un ordenamiento en el que concurren las características propias de todo ordenamiento jurídico: unidad, coherencia y plenitud. Se trata, por tanto, de un conjunto organizado y estructurado de normas jurídicas que posee sus propias fuentes, dotado de órganos y procedimientos aptos para emitirlas e interpretarlas, así como hacer constatar y sancionar, llegado el caso, las violaciones. Empero, además, reviste unas características particulares que lo diferencian de los derechos estatales y del DIP: el efecto directo de sus normas y su primacía sobre los ordenamientos jurídicos de los Estados miembros.

2. El DCE es un ordenamiento jurídico nuevo y propio de la UE, pero es un ordenamiento autónomo del DIP, pues se configura como un subordenamiento jurídico del ordenamiento jurídico internacional, esto es, una subespecie internacional sui generis — cuya esencia jurídica emerge de su profunda y compleja interrelación con los ordenamientos jurídicos internos - que origina normas comunitarias que no dejan de ser normas internacionales particulares. El DCE, en tanto que derecho internacional particular, crea normas internacionales que se aplican en el seno de la UE.

88 Rodríguez Carrión, A., Lecciones de derecho internacional público, Madrid, Tecnos, 2002, p. 298. 
3. El DCE está sujeto al derecho internacional universal o general en la misma medida en que lo están los sujetos internacionales, ya que éste se impone a sus destinatarios sin necesidad de una disposición de sumisión expresa al derecho internacional universal. La imposición de dicho derecho universal viene determinada en el propio derecho internacional universal.

4. Desde el plano formal y material, las normas del DCE son normas jurídico internacionales $\mathrm{y}$, por tanto, regidas por las normas de derecho internacional general aplicables a los tratados internacionales.

5. En tanto que normas particulares, a la hora de su aplicación las normas comunitarias tienen un doble límite: las normas imperativas o de ius cogens y, atendiendo al artículo 103 de la carta, las obligaciones dimanantes de ésta deben ser consideradas como superiores a las resultantes de otros tratados internacionales, incluidos los propios del DCE, prevaleciendo en contra de las mismas. 